$$
\text { 第第第 第 }
$$

筋甲的二脾惯粕

匈狀脾健量臟窎器

多腺藏常, 剔方

り機剔家消出法論

ב能出鬼長卜並 目

ゲ障家三肝二

1 碍鬼就臟供

喜 $=\vec{\nabla}$ 及試

量肝就

臟 $\vec{\gamma}$

渻及

答物

次

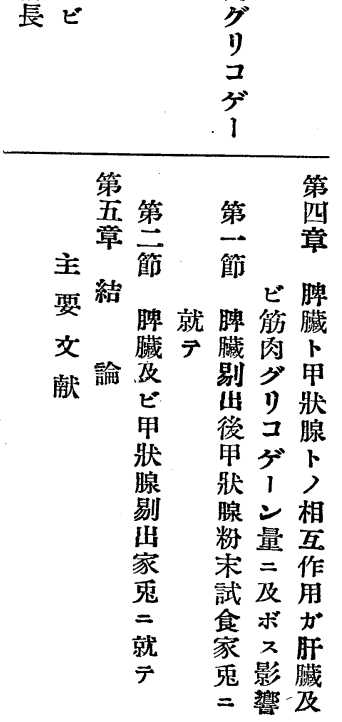

二影藏留
量脾

二臟

及 並

ボ二

學

院

學 京

生 都

醫國

學 大

$\pm$

學

村學

内

尾科

ス用

影 屔

躃 腺

二 ノ

就 肝

テ

藏

及

觔

肉

糖

原

留

$\underset{\text { 五 }}{\text { 无 }}$

勝

雄

述 


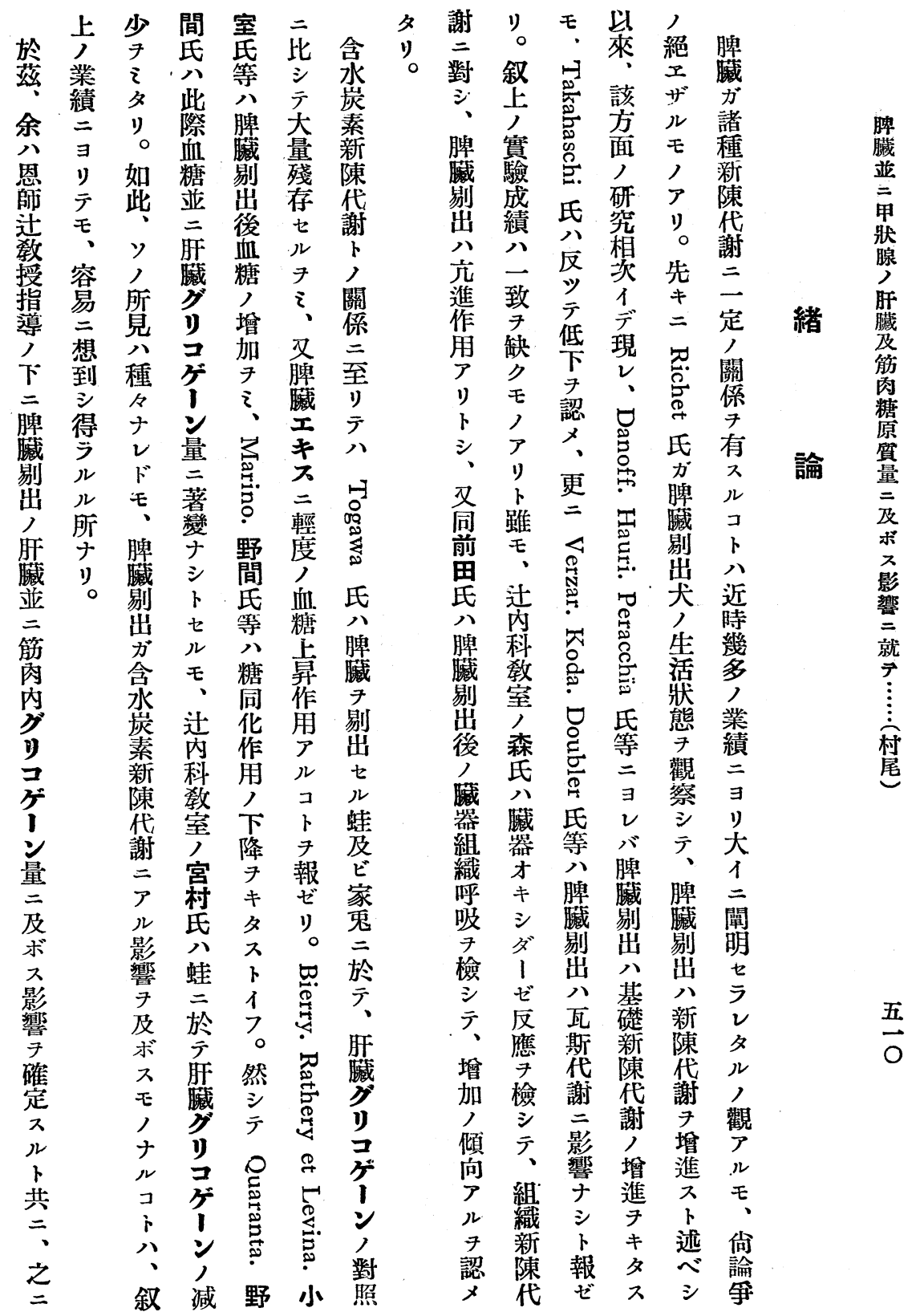




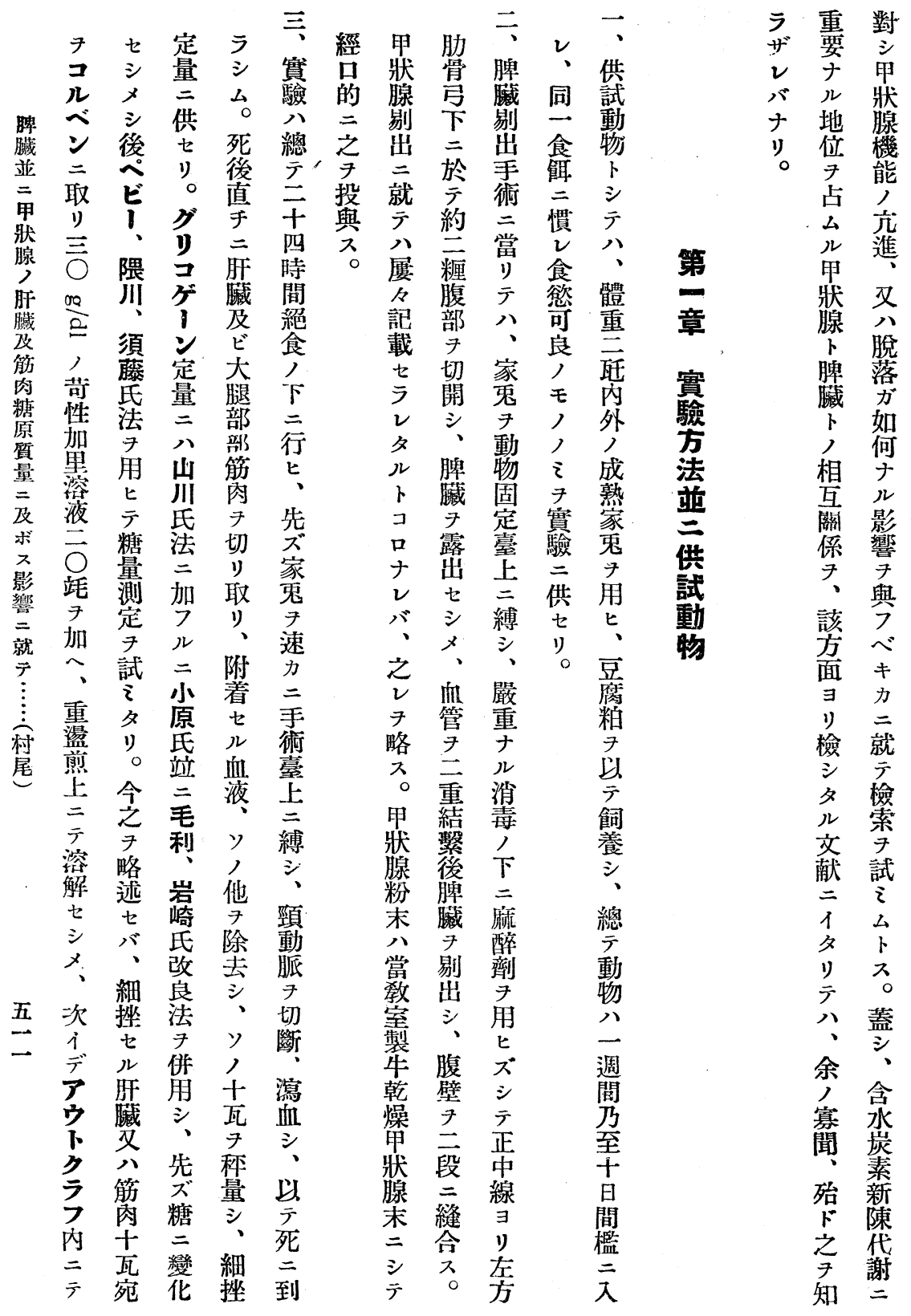




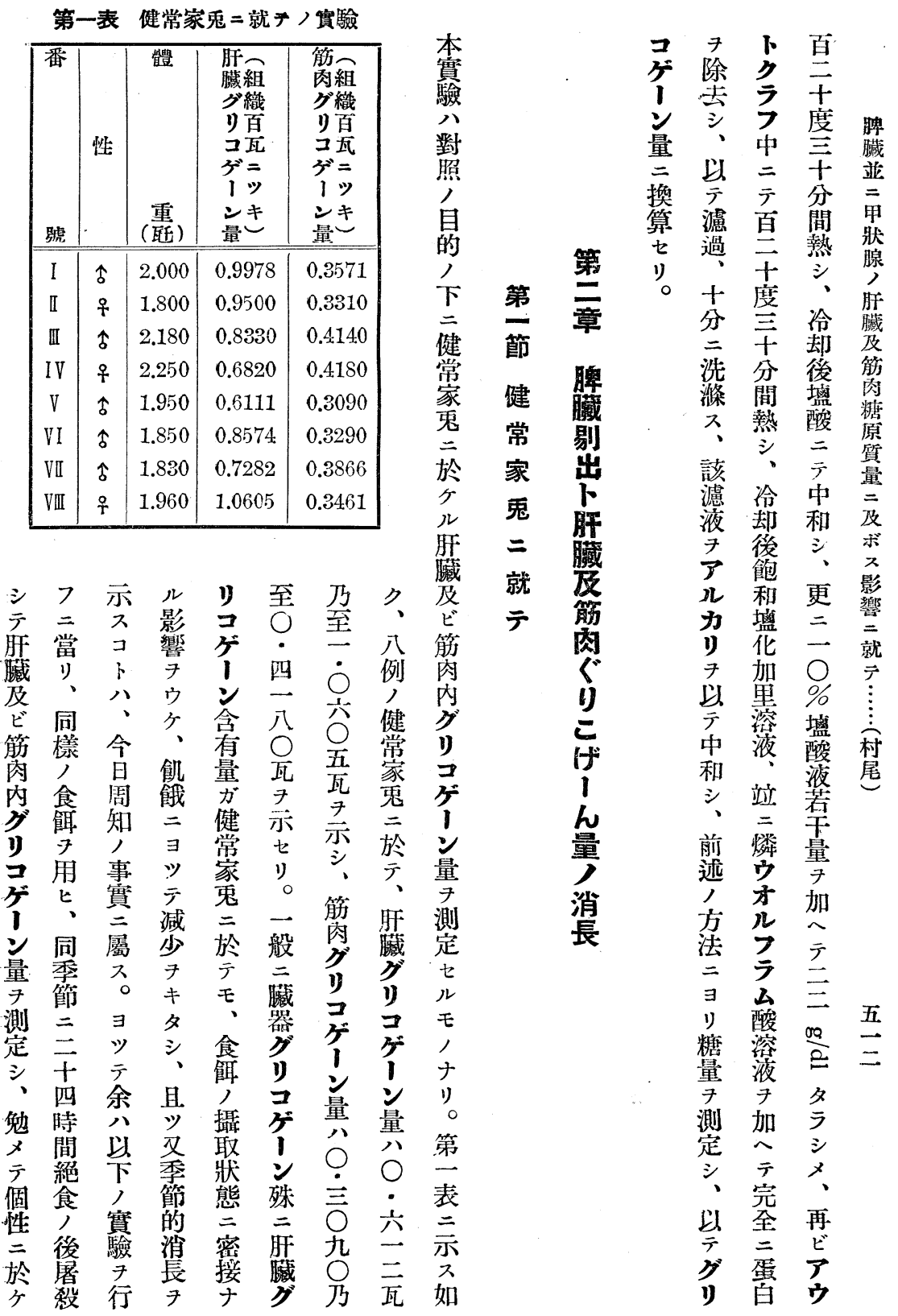




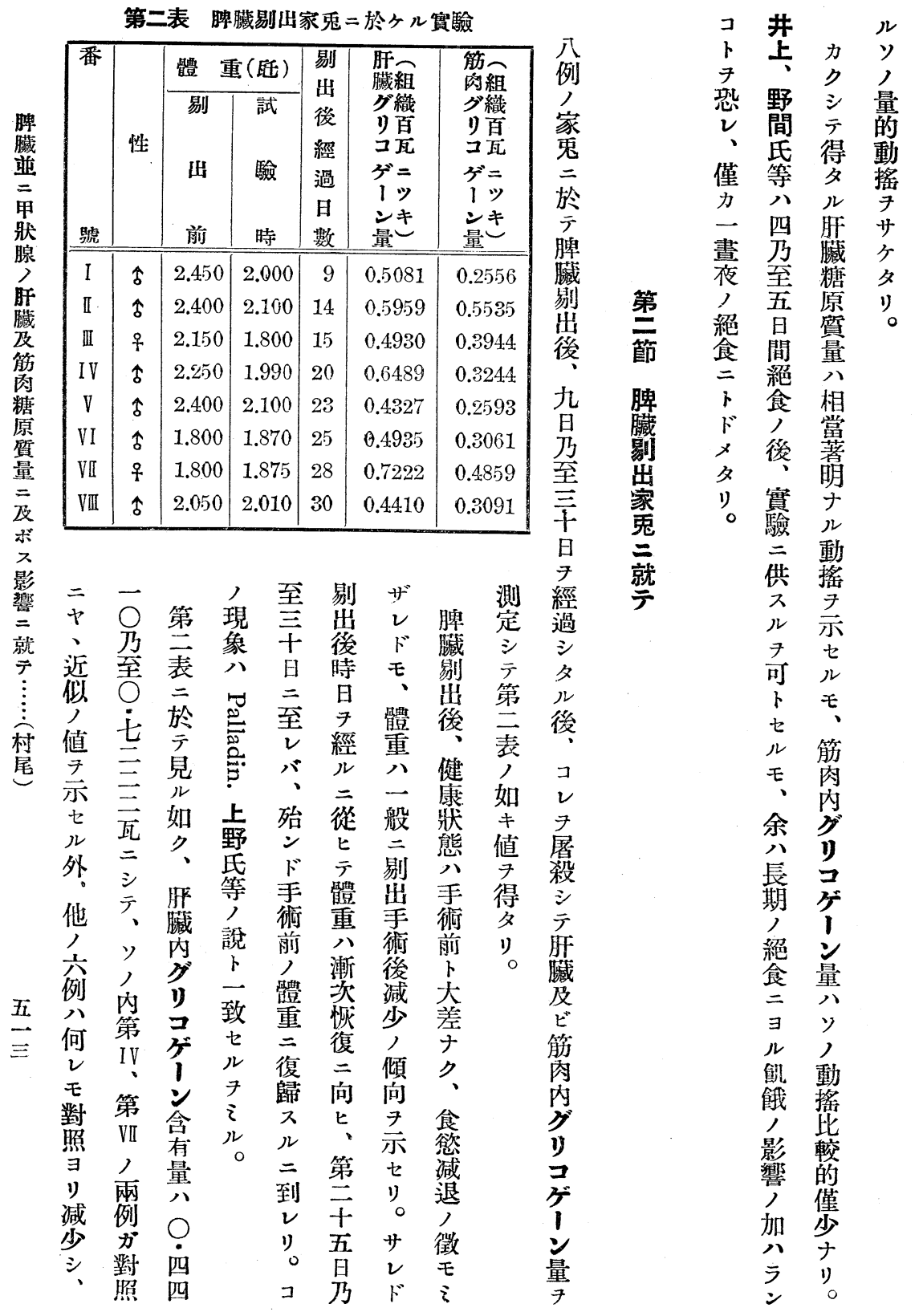




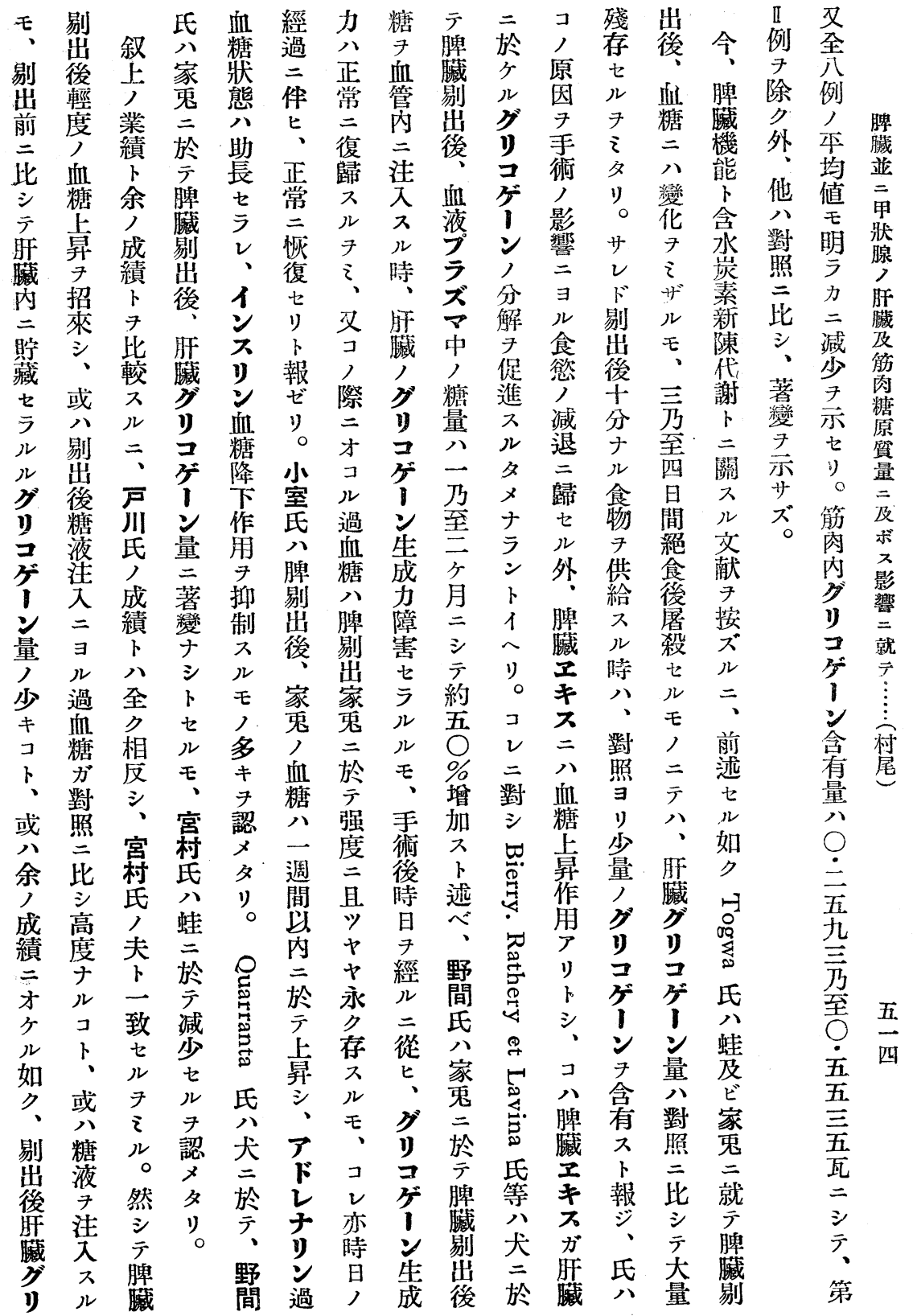




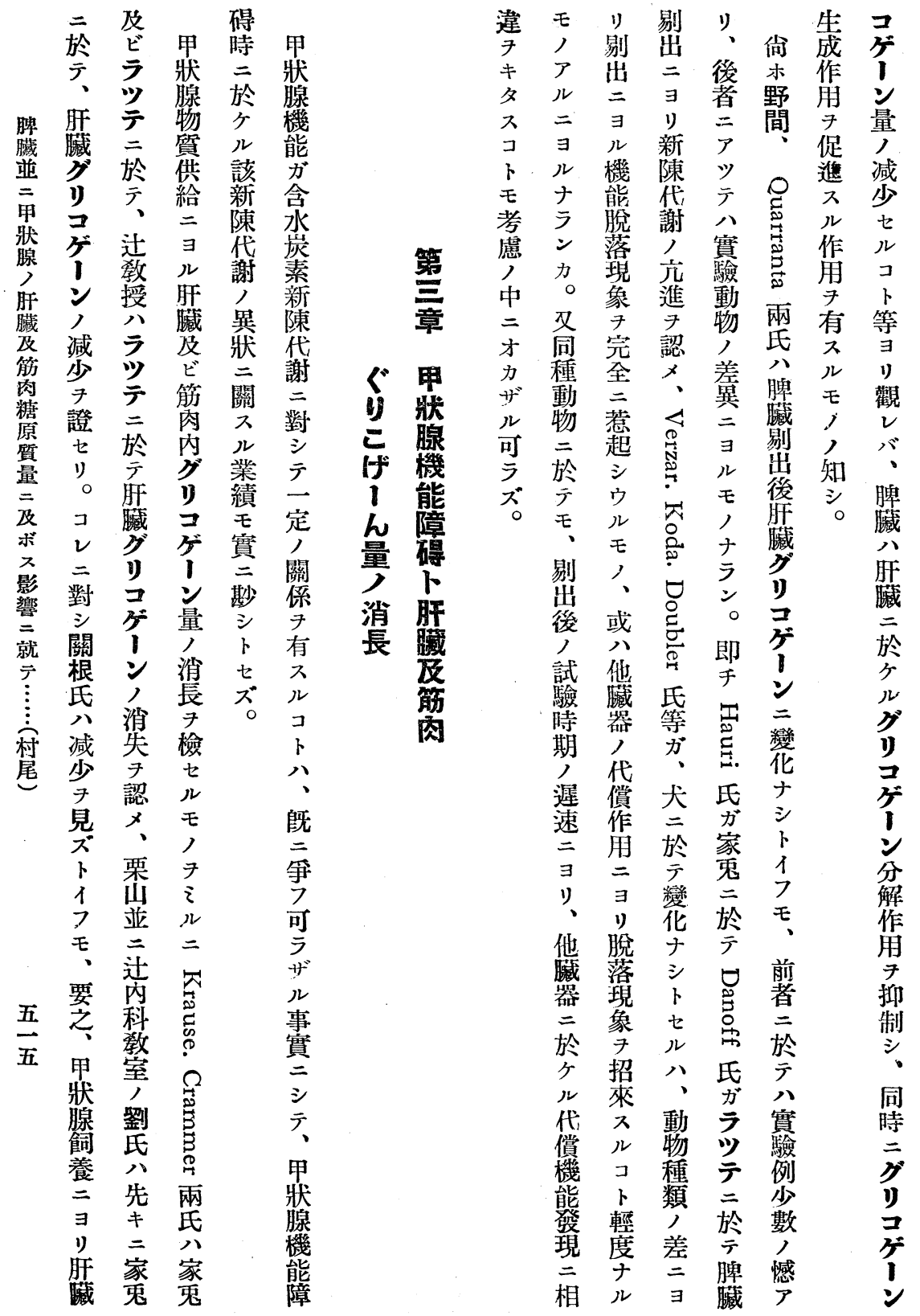


第三表 甲狀腺試食家鬼二就 $フ$ 實驗

\begin{tabular}{|c|c|c|c|c|c|c|}
\hline \multirow[t]{2}{*}{ 番 } & \multirow[b]{2}{*}{ 性 } & \multicolumn{2}{|c|}{ 體 重(䣶) } & \multirow[b]{2}{*}{$\begin{array}{l}\text { 試 } \\
\text { 食 } \\
\text { 日 } \\
\text { 數 }\end{array}$} & \multirow{2}{*}{ 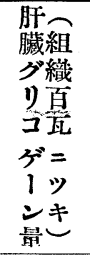 } & \multirow{2}{*}{ 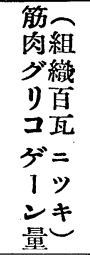 } \\
\hline & & $\begin{array}{l}\text { 試 } \\
\text { 食 }\end{array}$ & $\begin{array}{l}\text { 試 } \\
\text { 簽 }\end{array}$ & & & \\
\hline I & $\hat{\delta}$ & 2.000 & 1.650 & 6 & 0.4077 & 0.2708 \\
\hline II & $q$ & 2.050 & 1.510 & 8 & 0.4791 & 0.3966 \\
\hline II & q & 1.950 & 1.640 & 10 & 0.6144 & 0.8641 \\
\hline IV & 우 & 2.500 & 2.020 & 10 & 0.6876 & 0.5620 \\
\hline V & 우 & 2.020 & 1.500 & 10 & 0.4164 & 0.8710 \\
\hline VI & q & 1.860 & 1.350 & 11 & 0.7068 & 0.3850 \\
\hline VII & $\hat{\delta}$ & 1.900 & 1.550 & 11 & 0.5800 & 0.5302 \\
\hline VIII & $\hat{\delta}$ & 1.960 & 1.400 & 16 & 0.3246 & 0.24 .65 \\
\hline
\end{tabular}

第四表 甲狀腺剔出家鬼二就テノ實驗

\begin{tabular}{|c|c|c|c|c|c|c|}
\hline \multirow[t]{2}{*}{ 番 } & \multirow[b]{2}{*}{ 性 } & \multicolumn{2}{|c|}{ 體 重(配) } & \multirow[b]{2}{*}{$\begin{array}{l}\text { 剔 } \\
\text { 出 } \\
\text { 後 } \\
\text { 經 } \\
\text { 過 } \\
\text { 日 } \\
\text { 數 }\end{array}$} & \multirow[b]{2}{*}{ 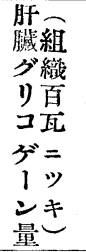 } & \multirow[b]{2}{*}{ 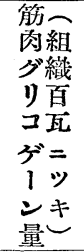 } \\
\hline & & $\begin{array}{l}\text { 剔 } \\
\text { 出 }\end{array}$ & $\begin{array}{l}\text { 試 } \\
\text { 驗 }\end{array}$ & & & \\
\hline I & 우 & 2.150 & 2.030 & 15 & 0.9520 & 0.3364 \\
\hline $\mathbb{I}$ & o & 2.220 & 1.820 & 17 & 0.7326 & 0.4586 \\
\hline III & $\hat{\delta}$ & 1.800 & 2.000 & 26 & 0.8723 & 0.5045 \\
\hline IV & $\hat{\delta}$ & 2.260 & 2.380 & $4: 1$ & 0.8816 & 0.4247 \\
\hline V & 占 & 2.520 & 2.400 & 41 & 0.9702 & 0.4501 \\
\hline VI & $\hat{\delta}$ & 1.900 & 1.940 & 30 & 0.8420 & 0.4936 \\
\hline VII & 우 & 1.800 & 2.000 & 44 & 0.9758 & 0.4143 \\
\hline VIII & $q$ & 1.970 & 2.060 & 44 & 1.4341 & 0.3343 \\
\hline
\end{tabular}

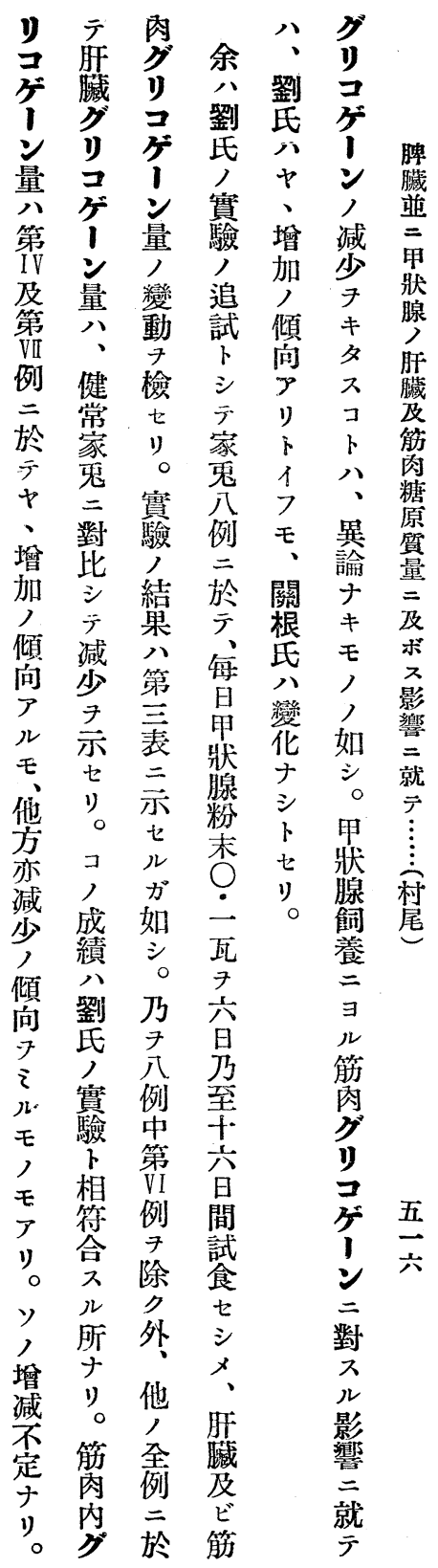

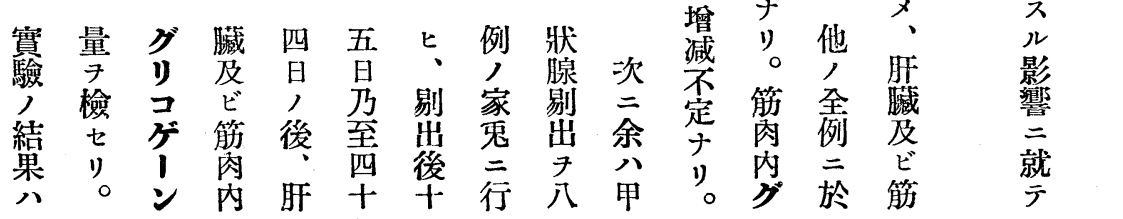


就 当

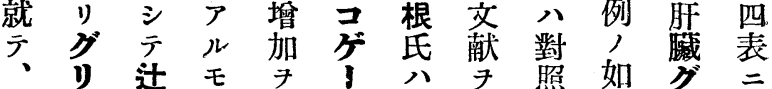

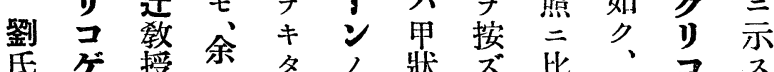
八1 1 惯七消腺儿比正志如

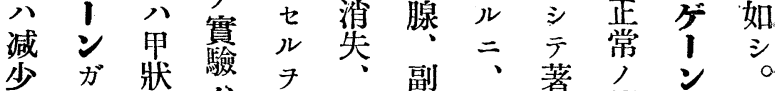
四夕三除楾り减腺氏認㐫○

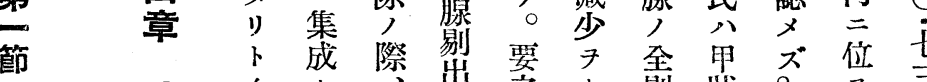

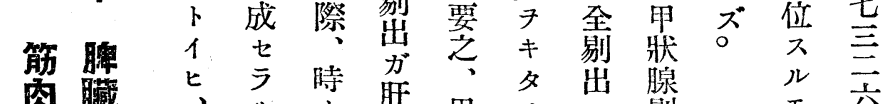
因臟、、時奛甲

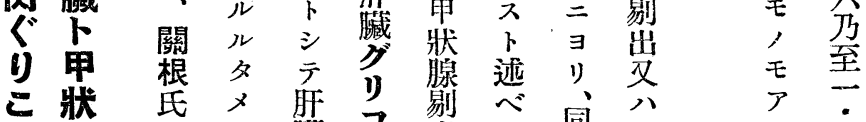

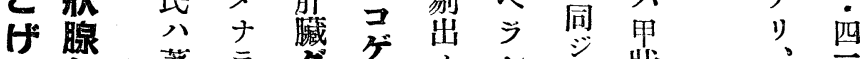

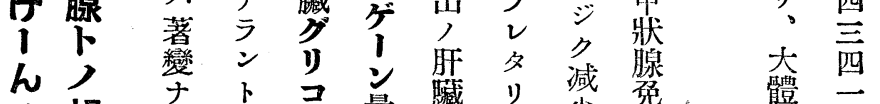

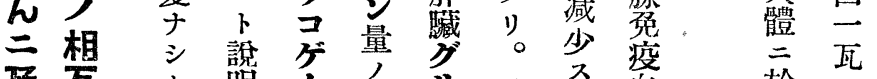

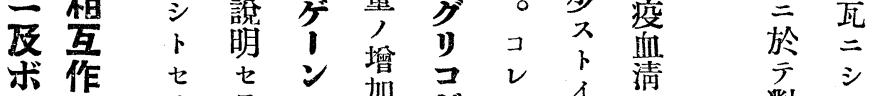

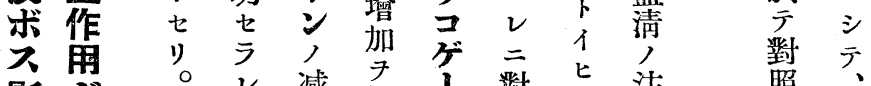
影。减招! 對七注照厂、

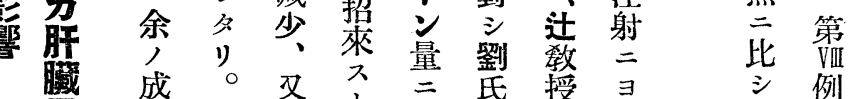
墼 成

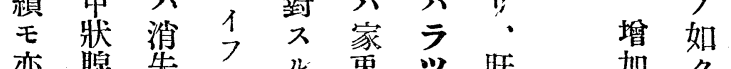
亦腺先 ᄀ

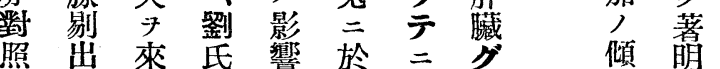
比符

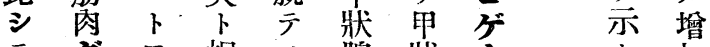
$\frac{\text { 五 }}{\text { 七 }}$

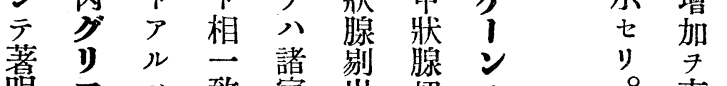

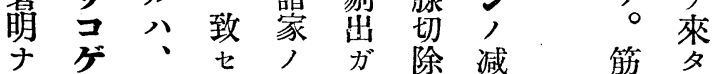

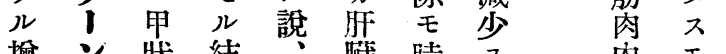
增 2 牀 結 臟. 時 $尹$ 內 $モ$ 减 對嘰 果 晌 グ

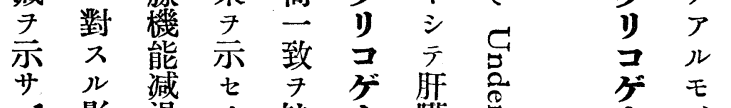

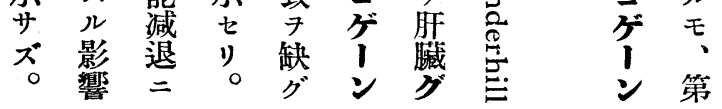




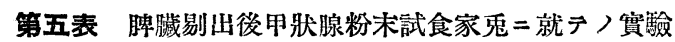

\begin{tabular}{|c|c|c|c|c|c|c|c|c|}
\hline 番 & 性 & $\begin{array}{c}\text { 體 } \\
\text { 脾 } \\
\text { 臟 } \\
\text { 剔 } \\
\text { 出 } \\
\text { 時 }\end{array}$ & $\begin{array}{c}\text { 重 } \\
\text { 甲 } \\
\text { 狀 } \\
\text { 腺 } \\
\text { 試 } \\
\text { 食 } \\
\text { 時 }\end{array}$ & $\frac{\text { (䣶) }}{\text { 試 }}$ & $\begin{array}{l}\text { 脾 } \\
\text { 藏 } \\
\text { 剔 } \\
\text { 出 } \\
\text { 後 } \\
\text { 經 } \\
\text { 過 } \\
\text { 日 } \\
\text { 數 } \\
\end{array}$ & $\begin{array}{l}\text { 甲 } \\
\text { 狀 } \\
\text { 腺 } \\
\text { 試 } \\
\text { 食 } \\
\text { 日 } \\
\text { 數 }\end{array}$ & 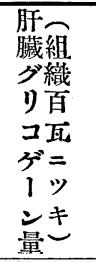 & $\begin{array}{l}\text { 筋へ } \\
\text { 肉組 } \\
\text { グ織 } \\
\text { り百 } \\
\text { コ瓦 } \\
\text { ぶニ } \\
\text { 1ッ } \\
\text { シキ } \\
\text { 量さ }\end{array}$ \\
\hline I & $\hat{\delta}$ & 2.500 & 2.210 & 1.800 & 28 & 10 & 0.4474 & 0.3629 \\
\hline II & 우 & 2.650 & 2.240 & 1.920 & 25 & 7 & 0.4739 & 0.4184 \\
\hline III & tै & 2.300 & 2.360 & 1.840 & 27 & 10 & 0.5658 & 0.3742 \\
\hline IV & 令 & 2.000 & 2.010 & 1.400 & 30 & 13 & 0.3107 & 0.2978 \\
\hline V & $\hat{\jmath}$ & 2.100 & 2.130 & 1.560 & 30 & 14 & 0.5494 & 0.4640 \\
\hline VI & 占 & 3.000 & 2.770 & 2.030 & 26 & 10 & 0.4858 & 0.4326 \\
\hline VII & 우 & 2.150 & 2.080 & 1.550 & 28 & 12 & 0.3987 & 0.3147 \\
\hline VIII & $\hat{s}$ & 2.000 & 1.730 & 1.550 & 24 & 11 & 0.3387 & 0.3170 \\
\hline
\end{tabular}

板 兩 $\exists$
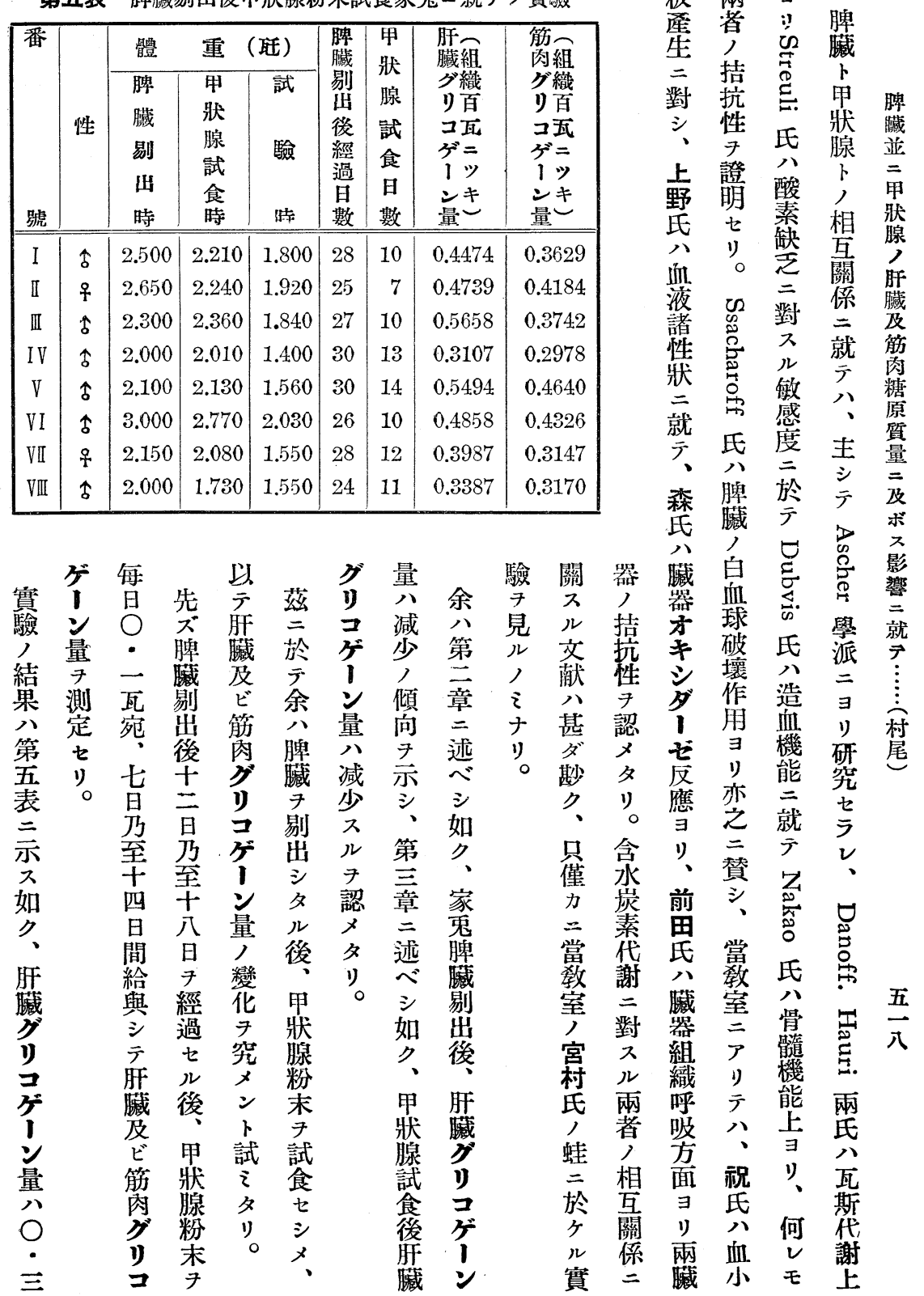
第六表 脾臟及ビ甲狀腺剔出家鬼二就テノ實驗

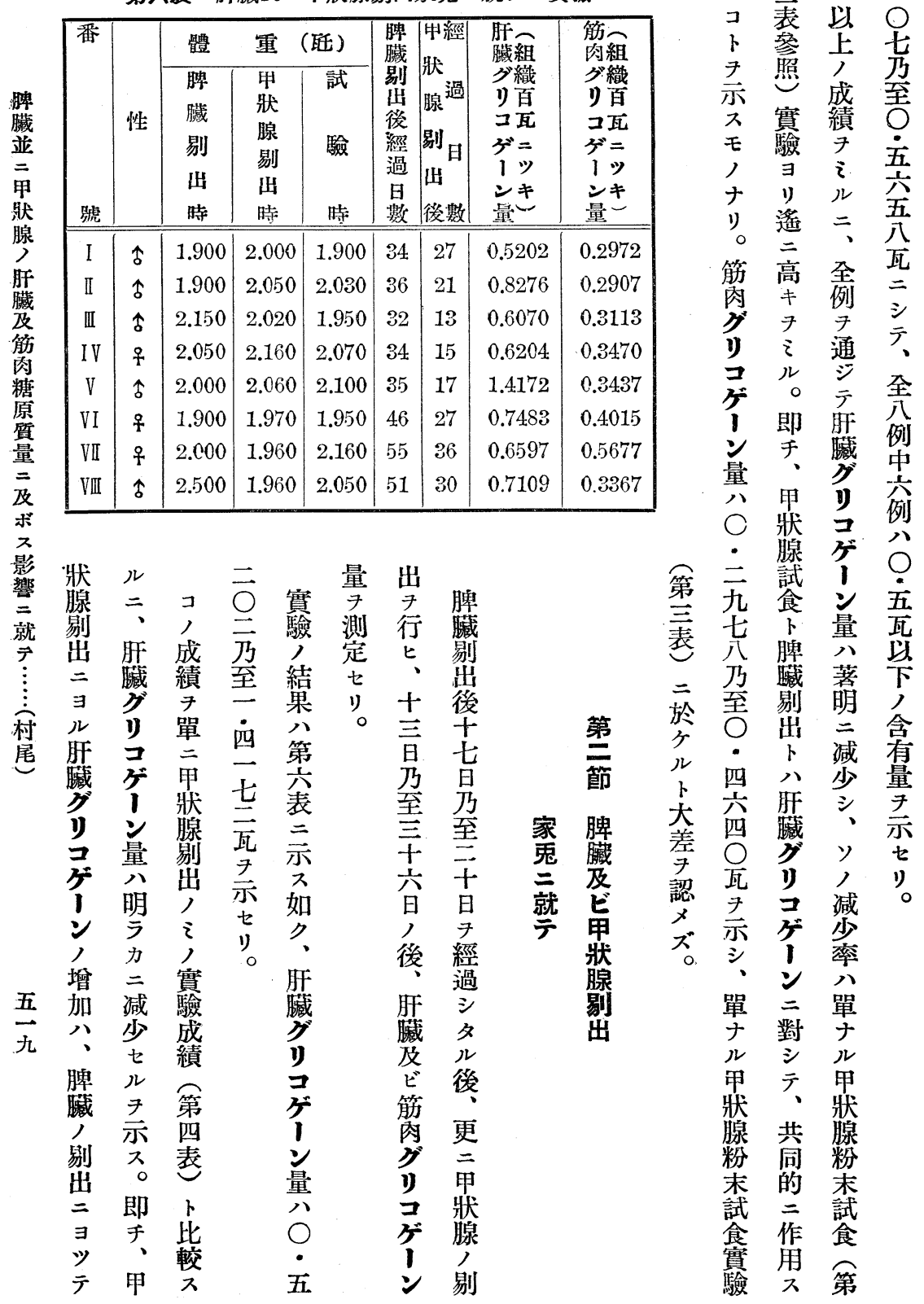




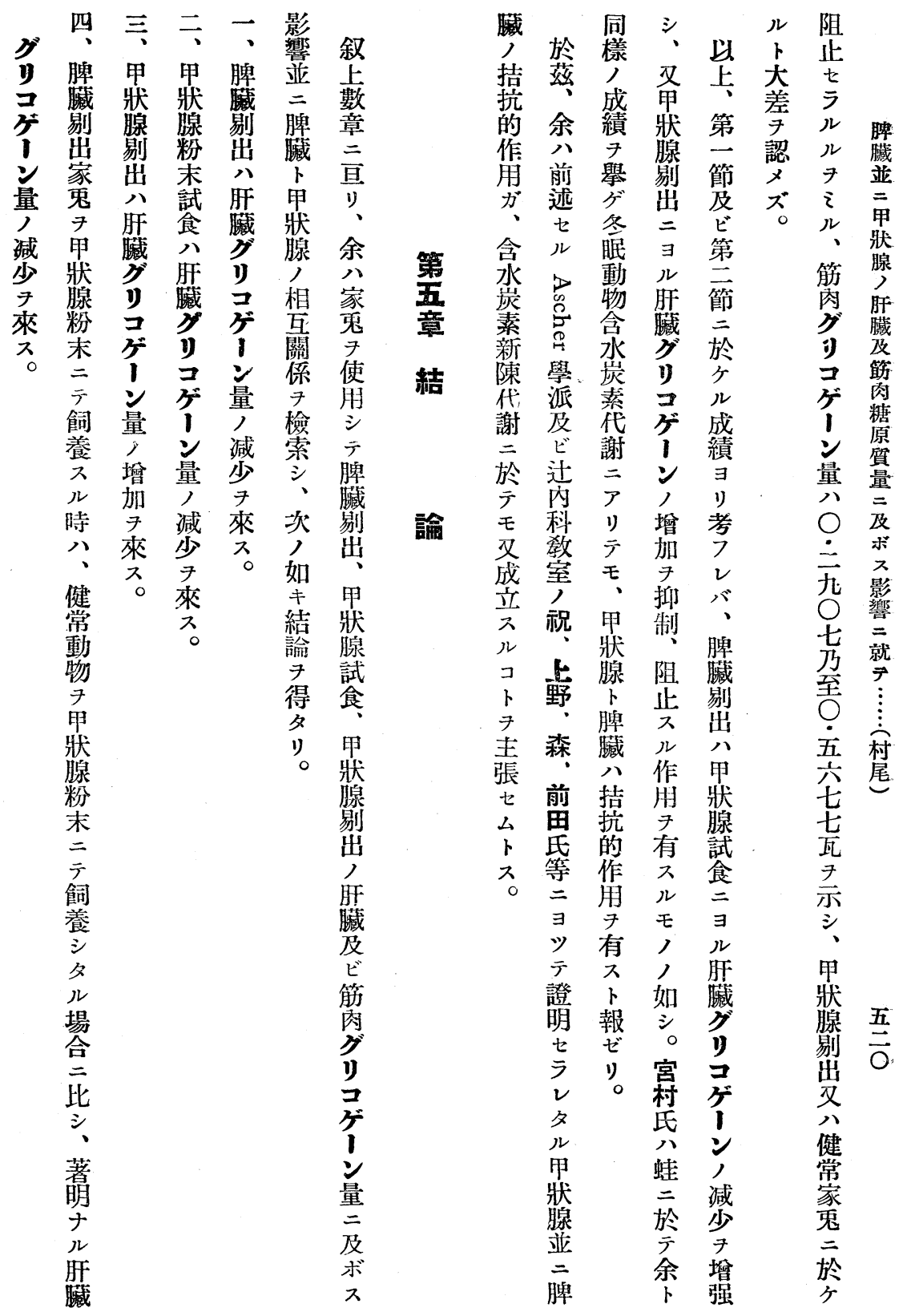




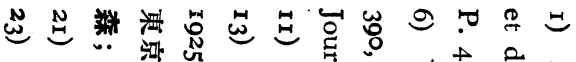

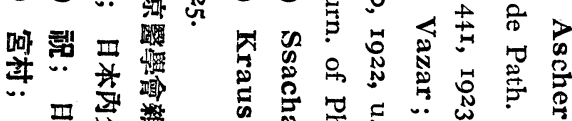

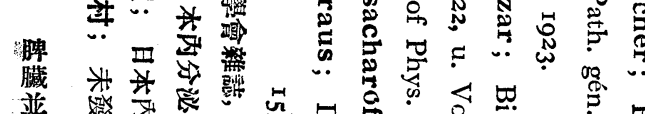

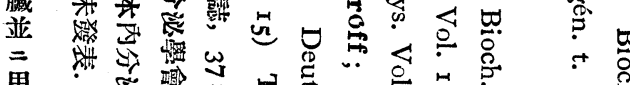

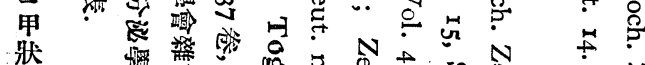

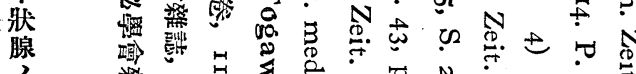

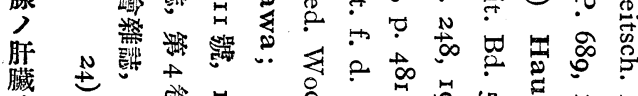
及

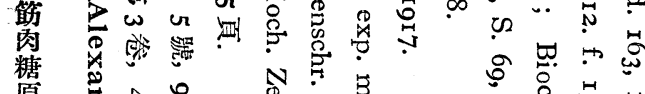

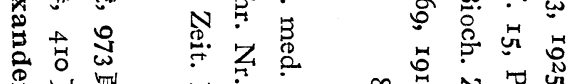

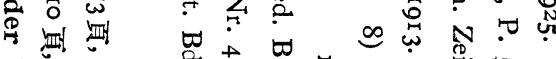

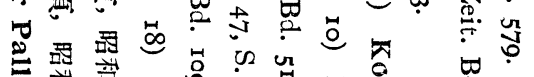

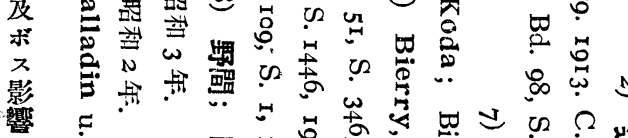

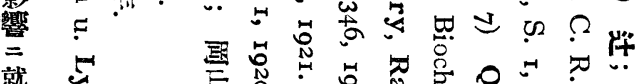

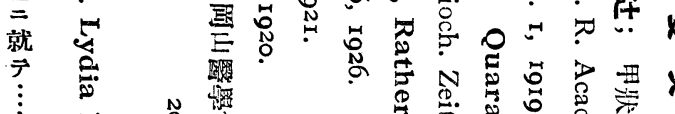

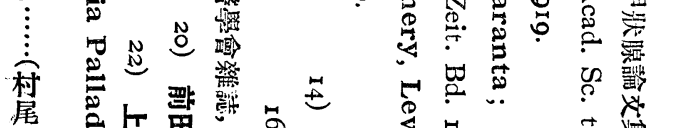

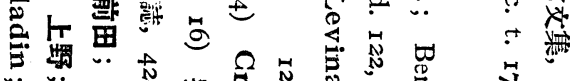

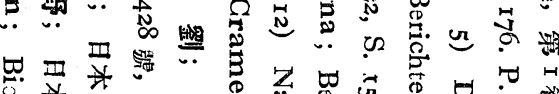

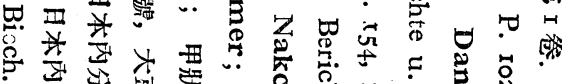

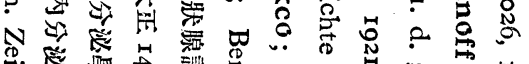

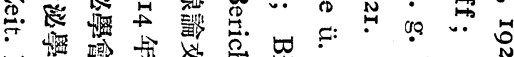

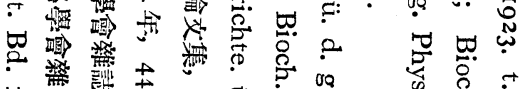

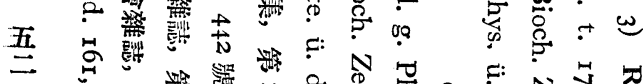

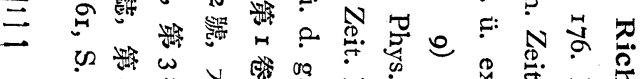

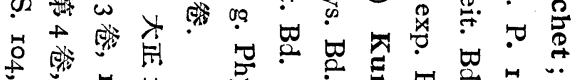

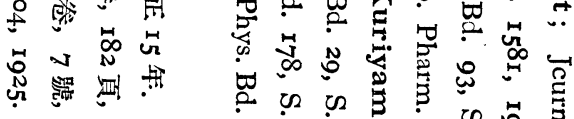

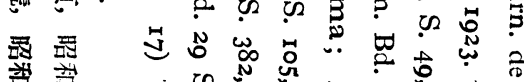

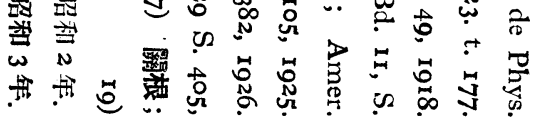

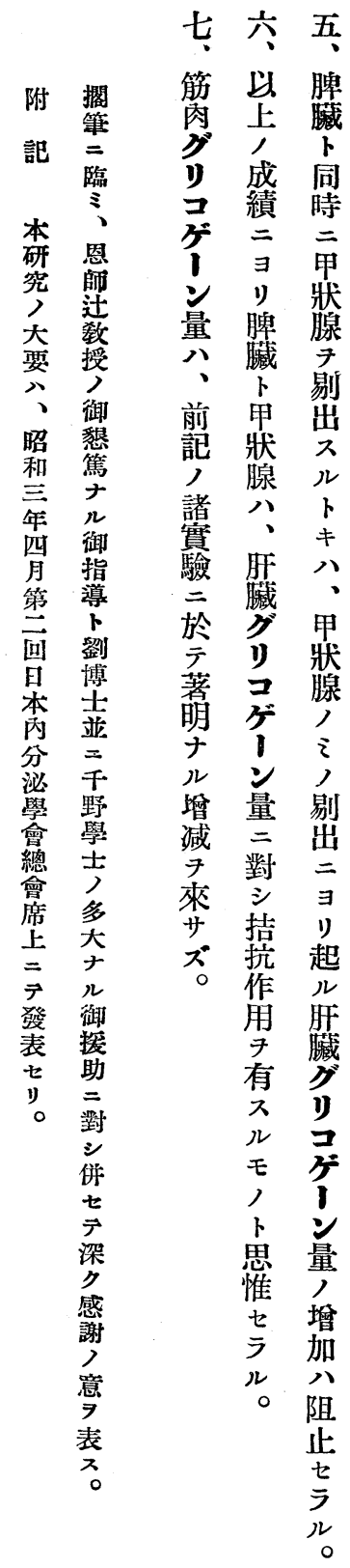




\section{FOLIA ENDOCRINOLOGICA JAPONICFI}

\begin{tabular}{lll}
\hline \hline Band VI & Juli & Heft 4 \\
\hline
\end{tabular}

\section{Ueber den Einfluss der Milz und Schilddrüse auf das Leber- und Muskelglykogen.}

Von

Dr. K. Murao.

(Aus der I med. Klinik der Kaiserl. Univers. zu Kyoto in Japan. Direktor: Prof. Dr. K. Tsuji.)

Der Verfasser bestimmt chemisch den Leber- u. Muskelglykogengehalt des Kaninchens, um den Einfluss der Milz und Schilddrüse auf den Kohlenhydratstoff wechsel zu studieren.

Kurz zusammengefasst sind die Resultate folgende:

I) Der Glykogengehalt der Leber nimmt nach der Splenektomie $\mathrm{ab}$.

2) Der Glykogengehalt der Leber nimmt bei Fütterung mit Schilddrüsenpulver $\mathrm{ab}$ und nach Thyreoidektomie zu.

3) Bei der Fütterung mit Schilddrüsenpulver zeigen die milzlosen Tiere deutlichere Verminderung des Leberglykogengehalts als die nichtoperierten.

4) Bei Tieren, die vorher thyreoidektomiert worden, hat die Milzexstirpation keinen erkennbaren Einfluss auf den Leberglykogengehalt.

5) Der Glykogengehalt des Muskels verändert sich bei diesen Versuchen nicht.

6) Daraus lässt sich der Schluss ziehen, dass die Milz 
bezüglich des Leberglykogens in antagonistischem Verhältnis zur Schilddrüse steht.

(Autoreferat)

\title{
Ueber den Einfluss der Nebennierenrinde und des Insulins auf das Leber- und Muskelglykogen.
}

\author{
Von
}

Dr. K. Murao.

(Aus der I med. Klinik der Kaiserl. Universität zu Kyoto in Japan. Direktor: Prof. Dr. K. Tsuji.

Der Verfasser bestimmte chemisch den Leber- und Muskelglykogengehalt des Kaninchens, um den Einfluss der Nebennierenrinde und des Insulins auf den Kohlenhydratstoffwechsel $z u$ studieren.

Die Ergebnisse lassen sich folgendermassen zusammenfassen :

A. Der Einfluss der Nebennierenrinde beim normalen Tier.

I) Bei der Darreichung von Nebennierenrindenpurver zeigt das Leberglykogen Neigung zur Vermehrung.

2) Sowohl die subcutane Injektion von Nebennierenrindenpulver als auch die Fütterung damit üben dieselbe Wirkung auf den Leberglykogengehalt aus. Nur ist die Wirkung in letzterem Falle stärker.

3) Die intraperitoneale oder die subcutane Injektion von Nebennierenrindenextrakt ruft Vermehrung des Leberglykogengehalts hervor, wobei der Wirkungsgrad bei der intraperitonealen etwas stärker als bei der subcutanen ist.

4) Der Glykogerigehalt des Muskels neigt bei diesen Versuchen mehr oder weniger zur Steigerung.

B. Der Einfluss des Insulins beim normalen Tier.

I) Der Glykogengehalt der Leber nimmt nach Insulininjektion $\mathrm{zu}$. 